\title{
Desarrollo de los derechos de la naturaleza en Ecuador
}

\section{Development of the rights of nature in Ecuador}

\author{
Girard David Vernaza Arroyo \\ girard.vernaza@utelvt.edu.ec \\ https://orcid.org/0000-0001-8591-6154 \\ Universidad Técnica Luis Vargas Torres: Esmeraldas, EC.
}

Recibido: $22 / 08 / 21$

Aceptado: 01/10/21

\section{Resumen}

La presente investigación tuvo como objetivo identificar los principales problemas conceptuales, legislativos y jurisprudenciales relativos a la naturaleza como sujeto de derechos y los que le son reconocidos en la Constitución ecuatoriana de 2008. Para desarrollar el tema se aplicó una metodología cualitativa con base en la circularidad hermenéutica, la cual permitió realizar una exploración inicial del tema para definir los objetivos y determinar el estado del arte mediante la revisión documental. La conclusión es que los derechos de la naturaleza carecen de un desarrollo teórico, legislativo y jurisprudencial que garanticen su comprensión a tenor de las exigencias y expectativas creadas con la entrada en vigencia de la Constitución de 2008.

Palabras clave: Naturaleza, derechos de la naturaleza, legislación ambiental, legislación, jurisprudencia.

\section{Abstract}

The objective of this research was to identify the main conceptual, legislative and jurisprudential problems related to nature as a subject of rights and the rights that are recognized in the Ecuadorian Constitution of 2008. To develop the subject, a qualitative methodology was applied based on the hermeneutical circularity, which allowed an initial exploration of the subject to define the objectives and determine the state of the art through documentary review. The main conclusion is that the rights of nature currently lack a theoretical, legislative and jurisprudential development that guarantees their adequate understanding in accordance with the demands and expectations created with the entry into force of the 2008 Constitution.

Keywords. Nature, rights of nature, environmental legislation, legislation, jurisprudence. 


\section{Introducción}

El estudio de los derechos de la naturaleza, y la subsecuente cualidad de sujeto de derechos que se le atribuyó en la Constitución ecuatoriana de 2008 (Asamblea Constituyente, 2008), ha sido abordado desde diferentes perspectivas; principalmente desde la ecología y los estudios ambientales, sin que exista hasta el presente un dimensionamiento del contenido y alcance jurídico de esos derechos, los elementos de la naturaleza a los que concretamente se les pueden reconocer y hacer efectivos, y los mecanismos legales necesarios para su desarrollo y defensa ante posibles violaciones del Estado o los particulares (Bustamante, 2019).

En este contexto, los derechos de la naturaleza han funcionado, hasta el presente, como un argumento adicional a los históricamente utilizados para defender los recursos naturales, los ecosistemas, los bienes ambientales y en general todo lo que pueda ser afectado por la acción humana, sin que se precise su ámbito específico de validez y distinción respecto al Derecho ambiental, que se ha ocupado en las últimas décadas de proveer un marco regulatorio y una estructura conceptual apropiada para la protección del medio ambiente.

Estudiar el desarrollo de derecho, sea de personas o entes distintos como la naturaleza o los animales; en algunos casos declarados sujetos con derechos; requiere al menos tres perspectivas; la construcción de un marco conceptual idóneo para su explicación y fundamentación teórica; el desarrollo legislativo, que debe incluir contenido y alcance, mecanismos de defensa como personas legitimadas para activarlos; finalmente la interpretación y aplicación de la legislación vigente, los jueces y tribunales que han debido resolver demandas por presunta violación de los derechos de la naturaleza.

Debe indicarse como punto de partida, que en el Ecuador ninguna de las tres perspectivas mencionadas ha tenido, hasta el presente, un desarrollo apreciable, razón que justifica el presente estudio que, tiene como propósito hacer una revisión del tema y construir un esbozado del estado del arte, a partir de la revisión de estudios teóricos, la legislación relativa la protección del ambiente y la jurisprudencia relevante de algunos tribunales ecuatorianos al respecto.

La pregunta a responder es la siguiente ¿Cuál es el estado de desarrollo de los derechos de la naturaleza en el Ecuador, desde el punto de vista teórico, legislativo y jurisprudencial? Para su desarrollo se aplicó una metodología cualitativa, que permitió extraer las ideas, conceptos, categorías y argumentos relativos a los derechos de la naturaleza, la sistematización de las normas jurídicas vigentes sobre el tema y las tendencias jurisdiccionales en los casos resueltos por presunta violación de derechos de la naturaleza desde 2008 hasta el presente. 


\section{Metodología}

La metodología cualitativa empleada tuvo entre sus objetivos como primer lugar, la identificación de los principales problemas teóricos y conceptuales relativos a la naturaleza como sujeto de derechos y los derechos que le fueron reconocidos en la Constitución de 2008. En segundo lugar, determinar el grado de desarrollo del marco regulatorio vigente para proteger los derechos de la naturaleza. En tercer lugar, se presenta la existencia de una línea jurisprudencial en materia de derechos de la naturaleza.

En el contexto del paradigma cualitativo se asumió la hermenéutica; tal como señala Leal (2005), se entiende por hermenéutica el arte de interpretar textos del cual sabemos que es un vocablo derivado del verbo griego Hemeneuo que significa interpretar y se justifica en una circularidad metódica justamente en el mismo texto y en la totalidad del mismo, además privilegia la intención del autor, al contexto y al medio de significación como sistematización.

En este trabajo, la referida circularidad está compuesta de la siguiente manera; exploración temática que se ve reflejada en los objetivos; comprensión inicial, constituida por el estado del arte; la comprensión profunda subyace en las respuestas que emergieron de las ideas, conceptos, categorías y argumentos relativos a los derechos de la naturaleza, su delimitación, contenido y alcance.

El estado del arte se presenta en el epígrafe relativo a la indefinición de la naturaleza como sujeto de derechos, donde se pone de manifiesto que en los estudios teóricos sobre el tema no se ha avanzado más allá de la apología de la naturaleza como sujeto de derechos, sin ahondar en las implicaciones teóricas y las consecuencias prácticas de romper con una tradición jurídica, según la cual solo las personas individuales o colectivas pueden ser sujetos de derechos, pero no entes no humanos como es la naturaleza.

Para analizar el ya referido punto de la investigación, se hizo una revisión de las principales publicaciones de los últimos diez años distribuida en libros, artículos científicos, reportes institucionales e información de diversa naturaleza, obtenida de sitios web verificados en su contenido. Una búsqueda exhaustiva de la información por autores, permitió verificar que tras la diversidad de publicaciones se encuentran los mismos investigadores que repiten enfoques y argumentos a través de diferentes medios.

Para determinar el nivel de desarrollo legislativo y jurisprudencial de los derechos de la naturaleza, se hizo una revisión de la legislación de contenido propiamente ambiental, puesta en vigencia desde 2008 hasta el presente; donde se constató que los derechos de la naturaleza se mencionan, pero no se desarrolla su contenido y alcance, ni la manera en que son protegidos en la legislación sobre minería, aguas, medio ambiente o 
delitos ambientales. Lo mismo se aprecia en la legislación procesal donde no se ha avanzado más allá de aplicar los mismos principios y norma procesal a sujetos tan diversos como las personas y la naturaleza.

Finalmente, para determinar el desarrollo jurisprudencial se revisaron varias sentencias de la Corte Constitucional del Ecuador relativas a los derechos de la naturaleza, donde se pudo determinar que no existe una línea definida en cuanto al contenido y alcance de tales derechos, los elementos de la naturaleza que deben ser considerados sujetos de los mismos y las obligaciones del Estado y la sociedad para proteger elementos de la naturaleza como ríos, bosques o ecosistemas frágiles, que no se limiten únicamente a la legislación ambiental tradicional y apliquen un nuevo paradigma derivado de la consideración de la naturaleza como sujeto.

\section{Indefinición de la naturaleza como sujeto de derechos}

Aquí se sistematizan los principales problemas conceptuales relacionados con los derechos de la naturaleza, pues si bien el sujeto a quien se atribuyen tales derechos parece evidente, el tema es más complejo cuando se trata de determinar qué es y qué no es naturaleza o a qué elementos se le atribuyen esos derechos y a cuáles no. La idea básica es que si la naturaleza considerada como un todo es sujeto de derechos, por mera lógica debería afirmarse que tiene la misma cualidad que cada uno de sus componentes. Dicho de otra manera, sí los derechos reconocen a una totalidad, por ejemplo, todos los seres humanos, no habría manera de negar la misma condición a cada una de las partes de esa totalidad, pues de lo contrario discriminaría a qué o quiénes dentro de la totalidad, aún reuniendo la propiedad esencial que les une de modo esencial no entra bajo el paraguas que cubre a esa totalidad. Si se pregunta ¿Qué es la naturaleza? La respuesta señalaría todo lo existente en el mundo tangible, desde las montañas hasta los animales grandes o pequeños que la habitan; inclusive las fuentes de agua, los microorganismos, los peces como parte de la especie marina, y así todo lo que puede ser percibido por el ser humano.

De los elementos referidos, surge la pregunta ¿Cuáles son sujeto de derechos y cuáles no? Al ser la Constitución de República la norma suprema donde se declara la naturaleza como sujeto de derechos, la respuesta debería buscarse en primer lugar, en su contenido, pero allí no aparece sino la palabra repetida para indicar su cualidad de sujeto, sin mayores precisiones que pudieran arrojar una luz sobre el modo interpretativo de esa condición que la asimila al ser humano en cuanto a su consideración jurídica.

Del mismo modo, no es posible encontrar una guía en la intención del constituyente, pues lo publicado sobre el tema por los actores involucrados en el proceso, apenas pasa de lo anecdótico; permitiendo hacer mención, por ejemplo, de las personas que intervinieron, los debates a lugar en las comisiones respectivas y en el pleno de la Asamblea Constituyente o en los medios de comunicación (Fundación Pacha Mama, 2008). 
A ello debe añadirse lo infructuoso de la búsqueda en los estudios de Derecho ambiental o de Derechos constitucional anteriores a la Constitución, pues su inexistencia es un hecho ya conocido en el país ante lo que podría llamarse una demanda o idea clara de consideración a la naturaleza como algo más que un objeto del Derecho, y como tal una fuente de recursos naturales.

Este planteamiento es reafirmado por un estudio reciente de F. Simón Campaña, ya desarrollado extensamente en la tesis doctoral defendida por el autor de esta investigación en la Universidad de Oriente de Santiago de Cuba (Vernaza, 2019). Según el ya referido autor, "la iniciativa de otorgarle derechos de la naturaleza provino de fuera del país, no estaba en la agenda de ninguno de los actores políticos nacionales o del movimiento indígena, incluso es posible identificar cierta oposición inicial del movimiento indígena por considerar que esto podía ser una amenaza a sus derechos territoriales" (Campaña, 2019).

Por tratarse de una idea proveniente del extranjero materializada en la Constitución, que tiene sus fundamentos en estudios con cierto grado de profundidad y sistematicidad, podría buscarse el modo de entender la naturaleza como sujeto de derechos que permita una definición precisa de todo lo que nos rodea. Sin embargo, tampoco existe ese desarrollo conceptual a nivel internacional; aparte de algunas referencias a teorías como la Gaia (Zaffaroni, 2011) o las elaboradas por los defensores de los derechos de los animales (Martínez \& Acosta, 2017), no es posible encontrar una elaboración a nivel conceptual de la naturaleza como sujeto en general, o como sujeto de derecho en particular.

Esa falta de desarrollo a nivel nacional o internacional sobre la naturaleza como sujeto de derechos coloca al estudioso en una encrucijada difícil de resolver, por cuanto no permite disponer de un aparato conceptual que identifique el ser concreto sobre el que recaen esos derechos reconocidos, y por tanto deja a los defensores de los mismos sin una guía segura para determinar cuándo se puede alegar una violación de los derechos atribuidos a la naturaleza como totalidad. Se podría decir que la naturaleza es lo que todos nombran, pero no alcanzan a definir, y esa definición es imprescindible cuando se trata de atribuirle consecuencias jurídicas.

La indefinición genera una serie de problemas jurídicos de sumo interés. Por ejemplo, no contar con una definición de la naturaleza a quien se le atribuyen derechos, resulta poco menos que imposible para el legislador identificar los deberes correlativos a esos derechos, los sujetos obligados y el contenido y alcance de esas obligaciones, así como las acciones concretas para hacerlos efectivos o reivindicarlos en caso de violación por otros sujetos de derechos.

También afecta la aplicación práctica de esa categoría jurídica que es la de sujeto de derechos, construida desde el Derecho romano como una cualidad inherente al ser humanos, dotado de conciencia y voluntad y capaz de actuar con base en fines que 
persigue de manera consciente. Si a un ente distinto al ser humano se aplica esa cualidad puede resultar complejo hacerla operativa, pues hasta donde llegan los conocimientos actuales, la naturaleza en general o cualquiera de sus componentes, carece de ellas. Finalmente, está el problema de aplicar la condición de sujeto de derechos de la naturaleza a sus partes esenciales.

Se puede inferir que cualquier persona estaría de acuerdo en que los animales son una parte esencial de la naturaleza, como los ríos, los bosques o cada árbol en particular, como también los virus que causan enfermedades y las plagas que afectan los cultivos destinados a la alimentación humana. Sin embargo, la ciencia ha realizado ingentes esfuerzos para eliminar los virus y exterminar el infortunio propagador de las plagas; al tiempo que incurre en la indiscriminada tala de árboles, contamina los ríos y se alimenta de animales domesticados, o se sirve de ellos para espectáculos o animales de compañía.

Lo que causa perplejidad es que mientras contienen los elementos indicados son considerados, sujeto de derechos, según la Constitución ecuatoriana, cada uno de ellos por separado no goza de esa protección, pues son utilizados como medios para satisfacer fines o necesidades humanas, en contra de la máxima moral que indica que los sujetos no deben ser empleados como un medio para alcanzar los fines de otros, pues son en sí mismos fines valiosos (Herrero, 2016).

En resumen, o bien todos los elementos de la naturaleza son sujeto de derecho por lo que el ser humano no podría moralmente utilizarlos como medios, o la cualidad de sujeto de derechos atribuida a la naturaleza tiene un carácter ontológico imposible de precisar con los instrumentos y categorías analíticas desarrolladas hasta el momento. La dificultad no se presenta únicamente ante los estudiosos, sino también al legislador como se verá en el apartado siguiente.

4. No hay desarrollo legislativo de los derechos de la naturaleza

En virtud de que no existe una determinación clara del sujeto sobre el que deben recaer los derechos atribuidos a la naturaleza, es evidente que su desarrollo legislativo se verá comprometido, tal como ha acontecido en los más de doce años de vigencia de la Constitución de 2008. Según el numeral 8 de su artículo 11, el contenido de los derechos se desarrollará de manera progresiva a través de las normas, la jurisprudencia y las políticas públicas, por lo que es necesario analizar en este punto cuál ha sido el grado de desarrollo de los derechos de la naturaleza mediante la legislación, y en el siguiente epígrafe su desarrollo por la vía jurisprudencial.

Lo primero que debe indicarse es que no existe una ley especial que desarrolle el contenido y alcance de los derechos de la naturaleza, ni una reserva de ley que obligue al legislador en tal sentido, como se deduce de la redacción de los artículos 71 y 72 . Por tanto, lo que se haya regulado en la legislación con posterioridad a 2008 puede responder a una obligación derivada de la propia Constitución, que atribuye la cualidad de sujeto 
de derechos a la naturaleza y le adjudica derechos específicos, o de una necesidad de coherencia normativa cuando se establece el marco regulatorio del uso, aprovechamiento o explotación de los recursos naturales.

Esta última aseveración es la que nos parece correcta y será confirmada con el análisis de la legislación ambiental dictada hasta el presente, donde en la mayoría de los casos la naturaleza aparece mencionada sin que se establezcan reglas concretas para su protección como sujeto de derechos, distintas a las habituales destinadas al proteger los recursos naturales y establecer obligaciones a los sujetos que interactúan en torno a los mismo. Aquí conviene hacer una distinción realizada por el jurista mexicano Raúl Brañes. Según el autor existen tres tipos de normas o de legislación ambientales (Brañes, 2001, pág. 11):

- La legislación común de relevancia ambiental o legislación de relevancia ambiental casual, integrada por las normas jurídicas expedidas sin ningún propósito ambiental, pero que regulan conductas que inciden significativamente en la protección del medio ambiente, sus orígenes datan del siglo XIX.

- La legislación sectorial de relevancia ambiental, integrada por las normas jurídicas expedidas para la protección de ciertos elementos ambientales o para proteger el medio ambiente de los efectos de algunas actividades, que es propia de las primeras décadas del siglo XX.

- La legislación propiamente ambiental, integrada por las normas jurídicas expedidas con arreglo a la moderna concepción que visualiza al medio ambiente como un todo organizado a la manera de un sistema.

En el caso del Ecuador, la legislación ambiental propiamente dicha es aquella dictada para imponer el régimen regulatorio de determinados recursos naturales, mientras que la legislación común de relevancia ambiental la que sin tener ese propósito incluye normas destinadas a la protección del ambiente o a sancionar las infracciones sobre el mismo. Entre las primeras, se encuentran las leyes orgánicas que, dictas después de 2008, establecen el marco normativo de recursos naturales en particular, mientras como ejemplo de las segundas identificamos al Código Orgánico Integral Penal que tipifica delitos y prevé sanciones para quienes atenten contra el bien jurídico constituido por ambiente el ambiente y la naturaleza o Pacha Mama.

Antes de entrar en el análisis de cada una de esas leyes que contemplan lo relevante para la protección de los derechos de la naturaleza, debe indicarse que en el año 2018, a propósito de cumplirse la primera década de una Constitución con derechos de la naturaleza, se reunió un grupo de juristas y ambientalistas para hacer un balance del desarrollo en ese tiempo, y el resultado fue más bien magro pues las diversas aristas exploradas no arrojaron sino tenues referencias la naturaleza o sus derechos sin ningún progreso digno de mención.

Los trabajos fueron publicados en el texto titulado Una década con derechos de la 
naturaleza (Maldonado \& Martínez, 2019), y contiene trabajos sobre la judicialización de los derechos de la naturaleza, los derechos de la naturaleza en el ámbito administrativo y en el ámbito penal, así como el estudio de la jurisprudencia constitucional relevante y algunos casos de conflictos socio ambientales donde se alega afectación a los derechos de la naturaleza.

Otro estudio que configura el estado de la cuestión sobre el desarrollo legislativo es el trabajo publicado por Diego Viteri Núñez titulado Los derechos de la naturaleza en la legislación Ecuatoriana, (Viteri, 2019), donde le autor hace un balance de la legislación propiamente ambiental dictada hasta ese momento y sus características principales en cuanto a los derechos de la naturaleza, llegando a la conclusión de ésta se menciona en esas disposiciones jurídicas, pero no existe un desarrollo del contenido y alcance de esos derechos que pueda considerarse apreciable.

Las leyes más importantes dictadas hasta la actualidad, por su carácter orgánico y la amplitud de sus regulaciones, son en orden cronológico la Ley de Minería, (Asamblea Nacional, 2009), la Ley Orgánica del Régimen de la Soberanía Alimentaria (Asamblea Nacional, 2009-a), la Ley Orgánica de Recursos Hídricos y Usos y Aprovechamiento del Agua (Asamblea Nacional, 2014-a) y el Código Orgánico del Ambiente (Asamblea Nacional, 2017).

En ninguno de esos cuerpos legales se desarrolla el contenido de la naturaleza, solo mencionan en su parte expositiva o como un deber general de las entidades del sector público o los ciudadanos concernidos por sus regulaciones, pero no se define el agua, los recursos mineros o los destinados a la alimentación como sujetos de derechos. Por lo que se refiere al régimen jurídico penal, donde consta en el Código un capítulo denominado delitos contra la naturaleza o Pacha mama, lo cierto es que los delitos tipificados en el mismo son los delitos ambientales comunes a cualquier legislación penal, algunos de los cuales ya existían en el Código Penal de 1971 bajo el título de delitos contra el medio ambiente.

Por otra parte, no se advierte en la configuración de esos delitos en el Código vigente, una influencia de los derechos de la naturaleza en la configuración jurídica de los delitos ambientales; a pesar de referir en el título como bien jurídico la naturaleza, ninguno de los delitos la protege a ella de un modo especial, es decir como sujeto de derechos, y no se tipifica infracción alguna que se configure cuando se violan los artículos 71 y 72 de la Constitución donde constan los derechos de la naturaleza.

En resumen, no existe en la actualidad en el Ecuador ningún desarrollo apreciable de los derechos de la naturaleza en el plano legislativo, pues no hay una ley especial que los desarrolle en su contenido y alcance, y la legislación ambiental solo menciona esos derechos y a la naturaleza como sujeto, pero no les atribuye consecuencia alguna por lo que se mantienen en el plano de las intencionalidades positivas que no se materializan en normas jurídicas operativas que permitan su adecuada protección como sucede en el caso de los derechos de las personas.

40 Desarrollo de los derechos de la naturaleza en Ecuador. - Eduweb, 2021, septiembre-diciembre, v.15, n.3. /33-47 
De modo que el legislador no ha extraído aún todas las consecuencias posibles de la condición de sujeto de derechos atribuida a la naturaleza, ni ha hecho realidad las esperanzas cifradas en su inclusión en la Constitución de 2008, que garantiza una mejor protección del ambiente y la naturaleza al atribuirle una condición similar a los seres humanos que son titulares de derechos. El discurso del constituyente finalmente no se ha traducido en el discurso del legislador ni del teórico del Derecho; debería evaluarse sí a pesar de las limitaciones señalada no pesan también sobre su protección en sede judicial, análisis que se realiza en el epígrafe siguiente.

5. No hay líneas jurisprudenciales sobre los derechos de la naturaleza

El concepto de líneas jurisprudenciales es complejo, pues se construye a partir de casos relevantes durante un período de tiempo para determinar las similitudes en las decisiones de los tribunales, generalmente del más alto tribunal de la justicia ordinaria o el de la jurisdicción constitucional, sobre un mismo tema en cuanto a normas aplicadas, argumentos utilizados y decisiones adoptadas. En el estudio de esos casos el investigador debe considerar la mayor cantidad de sentencias posibles, clasificarlas, catalogarlas y extraer los elementos comunes que le permitan construir una línea que identifique la doctrina sentada sobre la materia. En definitiva, debe escoger las sentencias que "tienen un peso estructural fundamental dentro de la línea por oposición a sentencias de menor importancia doctrinal” (López, 2009, pág. 160).

A partir de esos presupuestos el investigador Álvaro Andrés Motta Navas realizó una sistematización de las principales definiciones del concepto de líneas jurisprudenciales que conviene considerar por su importancia para el estudio de la jurisprudencia sobre los derechos de la naturaleza. Las principales características de las líneas jurisprudenciales, según su resumen, serían las siguientes (Motta, 2010, pág. 21).

1. Son elementos de análisis de jurisprudencia encaminadas a determinar el precedente judicial aplicable en casos futuros de características similares.

2. Exigen la realización de narraciones sobre determinado tema o problema jurídico tratado por la jurisprudencia, y requiere la presentación de una teoría jurídica completa sobre la materia.

3. Permiten la representación visual del tratamiento jurídico de una materia por parte de los jueces.

4. Son un método de identificación de decisiones previas que tienen fuerza vinculante y constituyen buenas razones para la estructuración de decisiones subsecuentes, ajustadas a los estándares fijados por la reiteración.

5. Son una técnica que permite la citación y referencia jurisprudencial dentro de esquemas de jurisprudencia libre o indicativa, lo que supone que los tribunales deben ajustarse a ella para evitar que sus decisiones sean revisadas y en su caso revocadas por un tribunal de instancia superior. 
6. Son un sinónimo de la regla o subregla de derecho, contenido en una providencia judicial para su aplicación obligatoria en casos con los que comparte características distintivas.

7. Son un método de organización de argumentos y razonamientos contenidos en las providencias judiciales.

8. Son un ejercicio metodológico encaminado a identificar una tendencia jurisprudencial vigente, con base en un patrón fáctico o en una institución jurídica específica, con vocación de uniformidad.

En cuanto método, la línea jurisprudencial consta de una serie de pasos delimitados por Héctor Santaella Quintero en su estudio sobre La línea jurisprudencial como instrumento esencial para conocer el Derecho, donde plantea que la aplicación de esta metodología consta de al menos cinco pasos que serían los siguientes (Santaella, 2016, pág. 7):

1. Identificar un problema jurídico claramente establecido que haya sido resuelto por la jurisprudencia. Definir un patrón fáctico y jurídico en el que típicamente se presente la cuestión indagada, que sirva de marco de referencia a la búsqueda de sentencias.

2. Realizar una investigación exhaustiva de los distintos pronunciamientos que se hayan ocupado del asunto en el lapso señalado como objeto de estudio.

3. Previa selección de las principales providencias (sentencias hito).

4. Ordenar y agrupar ese material en torno a posturas defendidas a lo largo del tiempo, que reflejen los debates internos que se han dado en la jurisprudencia y hagan apreciable la evolución y vicisitudes de la regla controlante del caso.

Ahora bien, en los estudios revisados no consta cuántas sentencias deberían revisarse aplicando ese método, para determinar una línea jurisprudencial sobre un tema determinado, que en nuestro caso serían los derechos de la naturaleza cuando son judicializados por los jueces ecuatorianos. Sobre ese particular realizó un estudio el investigador Farith Simón Campaña en el trabajo antes citado (Campaña, 2019). Según el autor, hasta el 10 de junio de 2018, es decir diez años después de ser catalogada la naturaleza como sujeto de derechos, la Corte Constitucional se había pronunciado por el tema en un total de 32 decisiones.

¿Es suficiente esa cantidad de decisiones para determinar una línea jurisprudencial? Si consideramos que entre ellas se encuentran no solo sentencias sino dictámenes, autos de admisión y resoluciones, la respuesta a esa pregunta sería negativa. Por otra parte; al no ser en todos los casos resoluciones sobre el fondo del asunto, en muchos de ellos los derechos de la naturaleza aparecen mencionados de paso o como argumento de refuerzo sobre algún punto de hecho o de Derecho, sin que haya una delimitación clara de los aspectos abordados en este ensayo, es decir de la determinación del sujeto de derechos naturaleza y de las normas que desarrollan sus derechos.

Como esa investigación mencionada llega hasta 2018, recurrimos al Boletín Anual de la Corte Constitucional correspondiente al año 2020, donde se constata que entre los casos seleccionados para su conocimiento y solución no consta ninguno sobre los derechos de

42 Desarrollo de los derechos de la naturaleza en Ecuador. - Eduweb, 2021, septiembre-diciembre, v.15, n.3. /33-47 
la naturaleza entre los más relevantes, aunque en sus estadísticas el organismo menciona como nuevos temas seleccionados los "derechos de la naturaleza y seguridad jurídica en el contexto de concesiones mineras que se habían emitido dentro de la zona parte de la reserva de biosfera Podocarpus-El Cóndor y de la reserva biológica Cerro Plate" (CCE, 2020, pág. 66).

Es decir, no se trata de casos sino de un caso respecto del cual todavía no existe una sentencia a favor o en contra de los accionantes. Otros autores, han hecho algunos intentos por catalogar la jurisprudencia sobre los derechos de la naturaleza y establecer sus características, pero al menos los que fueron consultados se quedan en la promesa porque no hay mucha fuente jurisdiccional de donde sacar algo provechoso sobre el tema (DPE, 2013).

Volviendo al trabajo citado con anterioridad, el autor tampoco llega a una conclusión sobre cuál es el concepto de la naturaleza a la que se le atribuye la cualidad de sujeto de derechos y se le adjudican derechos concretos, pues la Corte Constitucional en las sentencias que analizó es tan confusa como los teóricos mencionados en el primer epígrafe de este ensayo, refriéndose aquella como "ser vivo" cuyo reconocimiento como sujeto de derecho implica la ruptura del paradigma tradicional de relacionarse el ser humano con la naturaleza, y ser el origen de un nuevo paradigma radicalmente distinto (CCE, 2016, pág. 12).

Más desconcertante es que en la misma sentencia, unas líneas más abajo, la Corte señala que "los derechos de la naturaleza, al igual que el resto de derechos consagrados en la Constitución son inalienables, irrenunciables, indivisibles, interdependientes y de igual jerarquía; siendo un deber fundamental del Estado respetar y hacer respetar los derechos garantizados y establecidos en la norma constitucional” (CCE, 2016, pág. 13). Esa afirmación puede interpretarse de dos maneras distintas. La primera es que equipara la naturaleza y al ser humano en cuanto a sujeto de derechos de igual categoría, es decir que la naturaleza debe ser considerada y tratada como si fuera un ser humano, pues sus derechos tienen las mismas características que los de aquéllos.

La otra interpretación posible es que la Corte Constitucional recurre, como los teóricos de los derechos de la naturaleza y el legislador, a ese tipo de argumentos para que no quede por fuera la mención de la naturaleza como sujeto de derechos, sin atribuir a ese concepto un contenido concreto ni derivar del mismo alguna consecuencia práctica importante. Es como si cada quien por su lado y de manera independiente adoptara la misma pose grandilocuente sin considerar los problemas mencionados a lo largo de este escrito, pues desde ninguna de las perspectivas válida para abordar el tema se puede advertir un desarrollo considerable, que por lo menos marque una tendencia en el orden teórico o práctico.

En resumen, tampoco existe una línea jurisprudencial definida en cuanto al contenido y alcance de los derechos de la naturaleza; tampoco sobre el ser sobre el que recae la 
cualidad de sujeto y debe ejercer las facultades que se derivan de su adjudicación, pues en el nivel de la aplicación de la Constitución y las leyes tampoco se ha dado respuesta a los dilemas que presenta la cualidad de sujeto de derecho atribuida a la naturaleza.

En todo caso se ha impuesto la retórica, la mención, la referencia y la utilización de los derechos de la naturaleza como un argumento adicional a los tradicionales sobre la necesidad de proteger el ambiente y los recursos naturales. En ese contexto, se impone otra cuestión que debe ser desarrollada en futuras investigaciones, y es la pregunta hipotética de qué hubiera pasado si no se atribuye esa cualidad a la naturaleza y no se le adjudican derechos específicos.

Una conjetura válida es que todo seguiría como antes, es decir, que el Derecho ambiental estaría cumpliendo la misma función de regular el uso, aprovechamiento y explotación de los recursos naturales y los bienes ambientales dentro de los estándares definidos en la comunidad internacional y aquellos que se incorporen ene el Derecho interno.

Es probable que los derechos de la naturaleza hagan de ese Derecho ambiental un mecanismo de prevención protección y sanción más eficaz, pero hasta ahora no se ha demostrado que así sea en los 12 años de una naturaleza ecuatoriana con derechos.

\section{Conclusiones}

Como resultado de este proceso investigativo apoyado en su carácter epistemológico y metodológico de la circularidad hermenéutica, se exponen seguidamente los elementos conclusivos más importantes, entre aquellos encontrados en los documentos relativos a los derechos de la naturaleza y su cualidad de sujeto, que fueron el eje fundamental en la exploración inicial, el estado del arte y ahora en la comprensión profunda del tema estudiado.

1. Los principales problemas teóricos y conceptuales relativos a la naturaleza como sujeto de derechos y los derechos que le son atribuidos en la Constitución se refieren a dos aspectos distintos. En primer lugar, a la indefinición de la naturaleza en tanto sujeto, pues si bien desde un punto de vista general no habría dificultades en señalar que todo lo que nos rodea es naturaleza y por tanto sujeto, cuando se desciende a los elementos que la integran se puede apreciar que éstos no son sujetos de derechos.

2. El segundo problema es que no se ha definido, a nivel teórico, el contenido y alcance de los derechos de la naturaleza, ya que en las fuentes revisadas se da por entendido que ese contenido está precisado en la Constitución, cuando en realidad no es así porque los derechos que allí se enuncian si se interpretan literalmente el derecho a la existencia y mantenimiento de sus ciclos vitales es imposible de materializar, y el derecho a la restauración existe en el Derecho ambiental desde sus inicios.

3. Los problemas conceptuales se reflejan a nivel legislativo, donde no se ha desarrollado el contenido y alcance de los derechos de la naturaleza, ni se han determinado cuáles de entre todos los elementos que la integran se benefician de la 
cualidad de sujeto de derecho que se le atribuye a la totalidad. Y es que las leyes que establecen el marco regulatorio de la minería, el agua o los recursos forestales no dicen que esos recursos sean sujetos, ni que por ello deban recibir una protección especial distinta a la que brinda el tradicional Derecho ambiental.

4. Por lo que se refiere a la identificación de una posible línea jurisprudencial en materia de derechos de la naturaleza, la repuesta a esa cuestión es negativa, pues las sentencias de la Corte Constitucional hasta el momento se han limitado a repetir en algunos casos las ideas vagas formuladas por los teóricos, y en otros a transcribir el contenido de la Constitución, sin entrar a considerar aspectos de fondo como las peculiaridades del sujeto naturaleza, las formas de hacer efectivos sus derechos y los problemas que plantea.

5. A modo conclusivo, se afirma que no existe en la actualidad en el Ecuador, ni en la legislación vigente, ni en la jurisprudencia; un desarrollo apreciable de los derechos de la naturaleza; esta aseveración se basa en que no se ha dictado una ley especial que los desarrolle en su contenido y alcance, ni han establecido los tribunales una línea jurisprudencial que permita identificar cuáles de los elementos de la naturaleza adquieren la calidad de sujetos de derechos, cuál es el contenido y alcance de éstos y qué mecanismos legales e institucionales deben utilizarse para su protección y defensa ante eventuales violaciones por el Estado, las personas o las comunidades.

\section{References}

Acosta, A. (2008). La naturaleza como sujeto de derechos. Peripecias, 12-25.

Asamblea Constituyente. (2008). Constitución de la República del Ecuador. Montecristi: Registro Oficial de 20 de octubre.

Asamblea Nacional. (2009). Ley de Minería. Quito: Registro Oficial de 29 de enero.

Asamblea Nacional. (2009-a). Ley Orgánica del Régimen de la Soberanía Alimentaria. Quito: Registro Oficial de 5 de mayo.

Asamblea Nacional. (2014). Código Orgánico Integral Penal. Quito: Registro Oficial de 10 de febrero.

Asamblea Nacional. (2014-a). Ley Orgánica de Recursos Hídricos y Usos y Aprovechamiento del Agua. Quito: Registro Oficial de 6 de agosto.

Asamblea Nacional. (2017). Código Orgánico de Ambiente. Quito: Registro Oficial de 12 de abril.

Brañes, R. (2001). Informe sobre el desarrollo del Derecho Ambiental Latinoamericano. México: PNUMA.

Bustamante, F. (2019). Derechos de la naturaleza: análisis crítico de la jurisprudencia constitucional. En A. Maldonado, \& E. Martínez, Una década con derechos de la naturaleza (págs. 106-127). Quito: Abya Yala.

Campaña, F. (2019). Los derechos de la naturaleza en la constitución ecuatoriana del 2008: alcance, fundamentos y relación con los derechos humanos. ISMAT, 231-270.

CCE, No. 001-10-SIN (Corte Constitucional del Ecuador 18 de marzo de 2010).

CCE, No. 017-12-SIN-CC (Corte Constitucional del Ecuador 11 de julio de 2012). 
CCE, No. 218-15-SEP-CC (Corte Constitucional del Ecuador 9 de julio de 2015).

CCE, No. 218-15-SEP-CC (Corte Constitucional del Ecuador 17 de 11 de 2015).

CCE, No. 218-15-SEP-CC (Corte Constitucional del Ecuador 9 de julio de 2015-1).

CCE, No. 034-16-SIN-CC (Corte Constitucional del Ecuador 27 de abril de 2016).

CCE. (2020). Boletín jurisprudencial. Edición Especial Gestión 2020. Quito: CCE.

Clavero, B. (2011). Jurisprudencia Ecuatoriana sobre Derechos de la Naturaleza. El Correo, 1-5. Recuperado el 12 de febrero de 2021, de http://elcorreo.eu.org/Jurisprudencia-Ecuatoriana-sobre-Derechos-de-la-

Naturaleza?lang $=\mathrm{fr}$

DPE. (2013). Manual de normas y jurisprudencia de derechos de la naturaleza y ambiente. Quito: DPE.

Fundación Pacha Mama. (2008). la naturaleza también tiene derechos. Quito: Fundación Pacha Mama. Recuperado el 12 de abril de 2021, de http://derechosnaturaleza.blogspot.com/

Hazlewoo, J. (2017). La corte dicta sentencia en el primer juicio de derechos de la naturaleza del mundo. Intercontinental Cry, 1-6. Recuperado el 12 de febrero de 2021, de https://www.julihazlewood.com/artculosac\#: :text=La\%20Corte\%20Dicta\%20La\%20Sentencia,De\%20La\%20Naturaleza \%E2\%80\%9D\%20Del\%20Mundo\&text=El\%2011\%20de\%20enero\%20de,mundo $\% 20$ basada\%20en\%20una\%20constituci\%C3\%B3n.

Herrero, L. (2016). El fin en sí mismo y el sistema de la razón. International Journal of Philosophy, 374-379.

Larreátegui, F. (2019). Una mirada a los derechos de la naturaleza desde el Derecho Administrativo. En A. Maldonado, \& E. Martínez, Una década con derechos de la naturaleza (págs. 95-103). Quito: Abya yala.

Leal, J. (2005). La autonomía del sujeto investigador y la metodología de la investigación. Mérida: Ediciones Universidad de los Andes.

López, E. (2009). El Derecho de los jueces. Obligatoriedad del precedente constitucional, análisis de sentencias y líneas jurisprudenciales y teoría del derecho judicial. Bogotá: Legis Editores S.A.

Maldonado, A., \& Martínez, E. (2019). Una década con derechos de la naturaleza. Quito: Abya Yala.

Manzano, J. (2013). Si fuera sólo una cuestión de fe. Una crítica sobre el sentido y la utilidad del reconocimiento de derechos a la naturaleza en la Constitución del Ecuador. Revista Chilena de Derecho y Ciencia Política, 43-86.

Martínez, E., \& Acosta, A. (2017). Los Derechos de la Naturaleza como puerta de entrada a otro mundo posible. Direito e Práxis, 2927-2961.

Motta, A. (2010). Líneas Jurisprudenciales de la Constitucionalización de la Seguridad Social en Iberoamérica. Madrid: OISS.

Murcia, D. (2011). El sujeto naturaleza elementos para su comprensión. Quito: AbyaYala.

Pinto, I. (2017). La naturaleza como sujeto de derechos: análisis bioético de las Constituciones de Ecuador y Bolivia. Revista Latinoamericana de Bioética, 155-171. 
Revista de Tecnología de Información y Comunicación en Educación • Volumen 15, № 3. Septiembre-diciembre 2021

Prieto, M. (2013). Derechos de la naturaleza Fundamento, contenido y exigibilidad jurisdiccional. Quito: CEDC.

Roncal, X. (2012). La naturaleza...un sujeto con derechos. Apuntes para la reflexión. Revista de Investigación Educativa, 121-136.

Santaella, H. (2016). La línea jurisprudencial como instrumento esencial para conocer el Derecho Docencia y Derecho. Revista para la docencia universitaria, 1-10.

Simón, F. (2013). Derechos de la naturaleza: ¿innovación trascendental, retórica jurídica o proyecto político? luris Dictio, 1-30.

Suárez, S. (2013). Defendiendo la naturaleza: Retos y obstáculos en la implementación de los derechos de la naturaleza Caso río Vilcabamba. Energía y Clima, 1-13.

Vernaza, G. (2019). Los derechos de la naturaleza. Pilar básico para el buen vivir en Ecuado. Santiago de Cuba: Universidad de Oriente.

Viteri, D. (2019). Los derechos de la naturaleza en la legislación ecuatoriana. En A. Matilla, Reflexiones sobre el Derecho público (págs. 304-331). La Habana: Unión de Juristas de Cuba.

Zaffaroni, E. (2011). La Pacha Mama y el humano. Buenos Aires: Ediciones Madres de la Plaza de Mayo/Colihue. 